\title{
O problema da figuração do escravo em uma narrativa de Joaquim Manuel de Macedo ${ }^{1}$
}

\author{
The problem of slave figuration in a narrative by Joaquim Manuel de Macedo
}

\author{
Fernando C. Gil \\ Universidade Federal do Paraná - Paraná - Brasil
}

$\diamond$

\begin{abstract}
Resumo: O debate sobre a escravidão foi um dos eixos centrais de preocupação dos intelectuais e dos homens de letras, no Brasil, ao longo do século XIX. O objetivo deste artigo é examinar o caráter contraditório da visão abolicionista na narrativa "Pai-Raiol, o feiticeiro", de Joaquim Manuel de Macedo, a partir da figuração do escravo negro como personagem de ficção, bem como do sistema de valores que envolveria o mundo escravista, na perspectiva do escritor. Ao mesmo tempo, interessa identificar algumas articulações entre a representação do escravo no plano ficcional e certa concepção sobre o negro e o escravo negro corrente à época.
\end{abstract}

Palavras-chave: Personagem de ficção; Escravismo; Joaquim Manuel de Macedo; Narrativa rural

\begin{abstract}
The debate on slavery was one of the central axes of concern of intellectuals and men of letters in Brazil over the $19^{\text {th }}$ century. The aim of this article is to scan the contradictory feature of the abolitionist view in Joaquim Manuel de Macedo's "Pai-Raiol, o feiticeiro" narrative, based on the figuration of the black slave as a fictional character, as well as on the value system that would involve the enslaved world from the perspective of the writer. At the same time, it is interesting to identify some articulations between the representation of the slave in the fictional plane and certain conception on the black and the black enslaved current at the time.
\end{abstract}

Keywords: Fiction character; Slavery; Joaquim Manuel de Macedo; Rural narrative

$\mathrm{Na}$ apresentação do seu livro As vítimas-algozes: quadros da escravidão (1869), Joaquim Manuel de Macedo informa aos seus leitores que haveria duas maneiras de representar ficcionalmente a escravidão. Um primeiro caminho seria por meio do relato dos incalculáveis "sofrimentos do escravo, de árido deserto sem um oásis, de inferno perpétuo no mundo negro da escravidão" (MACEDO, 1991, p. 4). É o mal que o senhor inflige ao escravo. Um segundo mostraria o mal que "a sífilis moral da escravidão" faz ao seu senhor e à sua família, frutos dos "vícios ignóbeis, [d]a perversão, [d]os ódios, [d]os ferozes instintos do escravo, inimigo natural e rancoroso do seu senhor" (MACEDO, 1991, p.4). Para o escritor abolicionista que era Joaquim Manuel de Macedo e que punha a sua pena para o "desenlace menos violento desse nó terrível" que é a escravidão, a opção pelo

\footnotetext{
1 Este artigo faz parte da pesquisa, em curso, "A duplicidade da ficção rural brasileira: o estatuto do narrador, a representação do 'outro' e o 'estilo' da prosa rural", financiada pelo CNPq.
}

segundo caminho é a mais conveniente, pois interessaria, sobremaneira, influenciar a consciência e as atitudes dos senhores de escravos. Ela atuaria incisivamente sobre os perigos da escravidão em todos os âmbitos da vida do proprietário, perigos estes que não deixavam de conhecer no seu dia a dia, mas que se reproduzirão ad infinitum enquanto a escravidão não for banida de vez da sociedade brasileira.

Nada mais aparentemente avançado para um homem letrado, ali, no final dos anos 60 do século XIX, do que se posicionar a favor da emancipação da escravidão, "uma aspiração generosa da atualidade, e com a exigência implacável da civilização e do século" (MACEDO, 1991, p.1), no contexto da sociedade brasileira, que há cerca de três séculos convivia com a instituição da escravidão. Sobretudo se considerar que poucos anos antes, em 1865, com a derrota dos Confederados e o fim da guerra da Secessão, se pôs término à última grande nação escravista do mundo moderno, que eram os Estados Unidos, o que implicava, por sua vez, pressões mais intensas, de toda a 
ordem, sobre o nosso império escravocrata, que ao lado de Cuba resistia à abolição e a protelava como podia. Ao mesmo tempo, na fraca divisão social do trabalho do período, sabe-se que o homem de letras por aqui pouco se diferenciava do homem público, ou seja, o homem de letras era também o que intervinha no debate público, seja como membro do aparato burocrático do Estado imperial por meio de cargos administrativos, seja como político, deputado ou senador, como foi o caso de Macedo, eleito várias vezes como deputado.

$\mathrm{O}$ autor d'A moreninha, ao escrever as três narrativas que compõem os seus "quadros da escravidão", se situava, portanto, naquela linha em que a missão de intervenção pública se mistura com, ou exige, a ficção, no mesmo passo em que essa se mostra rente à demanda urgente da realidade. Nessa linha tênue, a opção de Joaquim Manuel de Macedo por encenar o mal que a escravidão faz ao senhor e à sua vida, ao que parece, não é somente uma escolha entre as possíveis, mas é a escolha possível. Isso porque a perspectiva de classe que Macedo consegue assumir é a das camadas dominantes proprietárias de terras e escravos. Essa consciência de classe compartilhada pelo nosso autor está assim presente não somente na narrativa que se tem em vista examinar, "Pai-Raiol, o feiticeiro", mas também nas outras duas que compõem o livro, "Simeão, o crioulo", e "Lucinda, a mucama". É dela que emana também uma das características centrais dessas histórias que é o que se pode chamar de "retórica do medo"2, a qual consiste na reiteração do perigo que representam os ardis, a dissimulação e a traição do escravo e/ou escrava ao senhor, à sua família e à propriedade. A escravidão como perigo permanente e sistemático à vida do proprietário se elabora tanto no âmbito do coração das situações narrativas, envolvendo sempre a dualidade conflitiva escravo/senhor, quanto nas próprias palavras/ voz do narrador que arma um discurso para além da matéria narrada, como se verá logo a seguir. De outra parte, se a consciência de classe movimenta e define parte significativa da dicção e da natureza das situações narradas, cabe destacar que o modo problemático de representação ficcional do escravo, a despeito de estar indissociavelmente também relacionado aos limites figurados por essa consciência, sugere encontrar na própria matéria social, isto é, na natureza social do escravo negro, os seus impasses e obstáculos.

Para deslindar com mais detalhe o argumento, é importante esboçar as linhas gerais da história de "PaiRaiol, o feiticeiro". Pai-Raiol fora arrematado, juntamente

\footnotetext{
2 Flora Sussekind se refere ao "imaginário do medo" no título dado pela ensaísta ao seu estudo sobre As vítimas-algozes em uma de suas edições (SUSSEKIND, 1991, p.XXI).
}

com a escrava Esméria, num último lote de escravos adquirido pelo fazendeiro Paulo Borges. Além de ser apresentado como desordeiro, desonesto e truculento, pairava sobre o escravo a fama de ter o poder da feitiçaria, particularmente tendo grande domínio da manipulação de ervas. Era de se crer, pelo que informa o narrador, que o último proprietário teria sido vítima de envenenamento provocado por Raiol. Como o quinto proprietário do escravo, Paulo Borges, preocupado apenas em aumentar o número de braços para a sua lavoura de açúcar, pouco se importa em ter informações sobre a vida pregressa dos escravos comprados. E, a princípio, o fazendeiro é só satisfação com a sua nova aquisição, por Raiol se mostrar dedicado tenazmente ao trabalho e por comprovar grande capacidade e energia para enfrentá-lo. Como o narrador não deixa nenhuma sutil aparência de pé para o leitor, ele mesmo desfaz aquilo que o personagem pretende esconder do seu senhor:

(...) mas Raiol não trabalhava com amor, trabalhava com raiva: dir-se-ia que intimamente revoltado contra a violência que o tornara escravo, provocava a fadiga, atormentava-se nos deveres obrigados da escravidão para atiçar as fúrias que esta acendera em seu seio (MACEDO, 1991, p. 89).

Adquirindo confiança de Paulo Borges, ele no trabalho do eito e Esméria no interior da casa-grande, como escrava doméstica, Pai-Raiol começa a traçar seu plano de vingança, que consistiria em obter a sua liberdade e também tomar posse da fazenda de Paulo Borges. Com Esméria tendo acesso direto à família do fazendeiro, o escravo açula o seu ânimo para que ela se insinue ao proprietáro de modo a se tornar sua amante. A escrava, não menos dissimulada do que o seu parceiro e antevendo certos gozos da nova situação, seduz Paulo, que se entrega à "embriaguez da luxúria mais desenvolta" dessa paixão. Com isso, Esméria ganha ascensão no interior da casa, no mesmo passo em que começa agir, a mando de Raiol, envenenando e matando os filhos do fazendeiro e a sua esposa, Teresa. Grávida de Borges, Esméria e seu filho obtêm alforria, restando-lhe, do plano traçado, apenas liquidar Paulo Borges com as ervas feitas pelo escravo-feiticeiro, na sequência do que, como herdeira e proprietária, ela libertaria Pai-Raiol e o alçaria a dono da fazenda. No entanto, duas situações, com saídas folhetinescas, fazem malograr os planos de Raiol. Primeiro, a desconfiança de Esméria com relação a Raiol, de que este poderia lhe atraiçoar e também a seu filho. Para estancar os objetivos do escravo, Esméria menciona as intenções do feiticeiro a outro escravo, Alberto, mostrando-lhe os riscos que todos na fazenda poderiam sofrer nas mãos de Raiol: ruim com proprietário branco, 
pior com proprietário negro. Ela consegue convencer Alberto a enfrentar Raiol. Paralelo a isso, Paulo Borges descobre os planos de Esméria e de Raiol pela octogenária Lourença, escrava maltratada por Esméria quando na sua nova situação na casa-grande. Faz ainda o proprietário saber que ela está lhe envenenando aos poucos. Ao final, à distância, Paulo Borges assiste à briga entre Alberto e Raiol, que culminará com a morte desse, jogado ao fundo de um "pedregoso precipício" por seu adversário. Alberto ganha a liberdade pelo feito, enquanto o fazendeiro desfaz o testamento que beneficiava Esméria e seu filho e manda prendê-la por estar por trás da morte de toda a sua família juntamente com Pai-Raiol.

Pelo resumo apresentado, já se pode notar que todos os elementos da narrativa são bastante esquemáticos e simplificados, presididos por uma voz narrativa que lhes impõe a sua perspectiva dos fatos e da vida. O caráter esquemático, ao menos a princípio, se enquadra na intenção de Joaquim Manuel de Macedo de atingir com certa "objetividade" e de modo aparentemente impactante a consciência dos proprietários de escravos. Daí Flora Sussekind anotar, no ensaio já mencionado, que a narrativa de Macedo se estrutura como "parábola". Como tal, a história de "Pai-Raiol, o feiticeiro", é exemplar e ilustrativa no sentido de demonstrar que "a escravidão é um mal, [que] transforma os cativos em algozes e os senhores em vítimas, escravos" (SUSSEKIND, 1991, p. XXII,), e tem como fim mostrar a necessidade da emancipação dos cativos. Assim, se o aspecto esquemático dos elementos narrativos tem função didática ao instrumentalizar o discurso literário em razão do projeto político da emancipação, este aspecto, que sugere caracterizar o mundo da representação ficcional como um todo, tem a sua origem, por assim dizer, "fora da literatura". Está relacionado ao próprio estatuto do escravo negro e à sua forma de inserção no mundo, o qual impregna a literatura de maneira inextrincável como parte que é da materialidade da vida social.

Não cabe, nos limites deste artigo, abordagem mais detida do problema no contexto da literatura brasileira do século XIX ${ }^{3}$; entretanto, creio que alguns elementos de "Pai-Raiol, o feiticeiro", possui alguma força de generalização com relação à representação ficcional em exame. Pode-se começar com aquilo que nos coloca no centro do problema que é a caracterização do escravo Paiol-Raiol na narrativa; a sua apresentação, no quinto capítulo, é longa, mas vale transcrição para os nossos objetivos:

\footnotetext{
Para uma introdução sobre o assunto, ver os já clássicos $O$ negro na literatura brasileira, de Raymond S. Sayers (Trad. Antônio Houaiss. Rio de Janeiro: O Cruzeiro, 1956), e Raça e cor na literatura brasileira, de David Brookshaw (Trad. Marta Kirst. Porto Alegre: Mercado Aberto, 1983).
}

Era um negro africano de trinta a trinta e seis anos de idade, um dos últimos importados da África pelo tráfico nefando: homem de baixa estatura, tinha o corpo exageradamente maior do que as pernas; a cabeça grande, os olhos vesgos, mas brilhantes e impossíveis de resistir à fixidade do seu olhar pela impressão incômoda do estrabismo duplo, e por não sabermos que fluição de magnetismo infernal; quanto ao mais, mostrava os caracteres físicos da sua raça; trazia porém nas faces cicatrizes vultuosas de sarjaduras recebidas na infância: um golpe de azorrague lhe partia pelo meio o lábio superior, e fenda resultante deixara a descoberto dous dentes brancos, alvejantes, pontudos, dentes caninos que pareciam ostentar-se ameaçadores; sua boca era pois como mal fechada por três lábios; dous superiores e completamente separados, e um inferior perfeito: o rir aliás muito raro desse negro era hediondo por semelhante deformidade; a barba retorcida e pobre que ele tinha mal crescida no queixo, como erva mesquinha em solo árido, em vez de ornar afeiava-lhe o semblante; uma de suas orelhas perdera o terço da concha na parte superior cortada irregularmente em violência de castigo ou em furor de desordem; e finalmente braços longos prendendo-se a mãos descomunais que desciam à altura dos joelhos completavam-lhe o aspecto repugnante da figura mais antipática (MACEDO, 1991, p. 82).

A caracterização de Pai-Raiol, como se percebe, começa pela descrição do tamanho desproporcional do seu corpo em relação às pernas ("o corpo exageradamente maior do que as pernas") e se fecha com a notação de outra desproporção, a do tamanho dos braços e das mãos ("que desciam à altura dos joelhos"). A desconformidade das pernas, dos braços e das mãos em relação ao resto do corpo, que sem o narrador dizer explicitamente alude a um processo de animalização ao sugerir a aparência do personagem a um símio, emoldura na verdade o elemento central da caracterização que são as feições de seu rosto. $\mathrm{O}$ quadro das deformidades com que é pintado Raiol tem continuidade na sua "cabeça grande" e nos seus olhos vesgos; esses expressam não somente a impressão hipnótica e hipnotizadora causada pelo seu estrabismo duplo (mais uma deformidade), mas sobretudo uma "fluição de magnetismo infernal". É dos olhos, mas não somente deles, que começam a tomar feição o aspecto e o caráter demoníacos do escravo.

Mas o que se destaca na caracterização de Pai-Raiol são as marcas da violência da escravidão impressas em sua face, em seus lábios e em suas orelhas, e o modo como o narrador as utiliza para ainda representar o personagem. Os traços da brutalidade contra o escravo não são sentidos ou compreendidos, nem por um triz, como atos de violência contra o corpo do escravo pelo ponto de vista do narrador. Ao contrário, os cortes no rosto, os lábios partidos e a parte da orelha arrancada naturalizam um 
modo de apresentação do escravo em que as marcas da violência corporais como que invertem as relações de causa e efeito em face das determinações sociais e históricas da brutalidade objetiva do mundo escravista; ou se não invertem, fazem com que se confundam e se misturem uma coisa à outra. Dito de outro modo, e pensando rente ao texto, é como se, por exemplo, a boca de "três lábios" (marcas da brutalidade escravista) que "pareciam ostentar-se ameaçadores" e por onde se projetava o seu riso "hediondo por tamanha deformidade" fossem "próprias" às feições de Raiol, portanto "naturais" a ele; por outro lado, a visão da brutalidade que naturaliza o seu próprio efeito no corpo do escravo é sobretudo constitutiva da perspectiva de classe do próprio narrador. A resultante que compõe o todo da visão do narrador é mesmo o "aspecto repugnante da figura antipática" do escravo, aspecto esse em que a violência é essencializada como intrínseca deformidade ao escravo negro como personagem ficcional.

Mas a atitude deformadora, se ganha na caracterização do escravo as suas tintas mais fortes, não se limita a esse. Não seria errado dizer que a escravidão, onde toca, deixa a sua marca de deformidade, o que se põe na perspectiva mesmo de Joaquim Manuel de Macedo, por entendê-la como o "cancro social, abuso inveterado que entrou em nossos costumes" (MACEDO, 1991, p. 2). Nesse sentido, a função de Pai-Raiol como feiticeiro entraria também nessa porção de negatividades hediondas trazidas tanto pela escravidão como pelo negro vindo d'África. Isso não somente como feiticeiro, mas a própria "feitiçaria" como um ritual primitivo, bárbaro e grotesco ${ }^{4}$. A passagem sobre esse ponto está contida nos três primeiros capítulos que constituem um relativo longo comentário/ representação a respeito da natureza do que supostamente seria o feiticeiro e a feitiçaria, como também em parte é o começo das outras duas narrativas de Vítimas-algozes em que o narrador, antes de entrar propriamente no entrecho, apresenta comentários, opiniões e cenas sobre a matéria que será objeto de representação nos capítulos seguintes. Para os nossos limites, gostaríamos de nos deter no trecho que segue, a fim de estabelecer algumas relações com a caracterização do personagem escravo:

O feitiço tem o seu pagode, seus sacerdotes, seu culto, suas cerimônias, seus mistérios; tudo porém grotesco, repugnante, e escandaloso.

O pagode é de extraordinário uma casa solitária; o sacerdote é um africano escravo, ou algum digno descendente e discípulo seu, embora livre ou já liberto,

\footnotetext{
4 Raymond S. Sayers, em seu ensaio O negro na literatura brasileira, nota que há desde o romance Maria ou a menina roubada (1852), de Teixeira e Sousa, um conjunto de personagens negros feiticeiros que formariam uma espécie de linhagem na literatura brasileira (SAYERS, 1958, p. 319).
}

e nunca falta a sacerdotisa de sua igualha; o culto é de noute à luz das candeias ou do braseiro; as cerimônias e os mistérios de incalculável variedade, conforme a imaginação mais ou menos assanhada dos embusteiros.

Pessoas livres e escravas acodem à noute e à hora aprazada ao casebre sinistro; uns vão curar-se do feitiço, de que se supõem afetados, outros vão iniciarse ou procurar encantados meios para fazer o mal que desejam ou conseguir o favor que aspiram.

Soam os grosseiros instrumentos que lembram as festas selvagens do índio do Brasil e do negro d'África; veemse talismãs rústicos, símbolos ridículos; ornamentamse o sacerdote e a sacerdotisa com penachos e adornos emblemáticos e de vivas cores; prepara-se ao fogo, ou na velha e imunda mesa, beberagem desconhecida, infusão de raízes enjoativas e quase sempre ou algumas vezes esquálidas; o sacerdote rompe em dança frenética, terrível, convulsiva, e muitas vezes, como a sibila, se estorce no chão: a sacerdotisa anda como doida, entra e sai, e volta para tornar a sair, lança ao fogo folhas e raízes que enchem de fumo sufocante e de cheiro ativo e desagradável a infecta sala, e no fim de uma hora de contorções e de dança do demônio, de ansiedade e de corrida louca da sócia do embusteiro, ela volta enfim do quintal, onde nada viu, e anuncia a chegada do gênio, do espírito, do deus do feitiço, para o qual há vinte nomes cada qual mais burlesco e mais brutal.

Referve a dança que se propaga: saracoteia a obscena negra e o sócio, interrompendo o seu bailar violento, leva a cuia ou o vaso que contém a beberagem a todos os circunstantes, dizendo-lhes: "toma pemba!" e cada qual bebe um trago de pemba imunda e perigosa. (MACEDO, 1991, p. 74.)

A passagem, como se mencionou, não está articulada ao entrecho; nesse sentido, não tem a força da representação propriamente de uma cena, mas também não se situa estritamente no âmbito do comentário, embora, como se nota, esteja prenhe de ajuizamentos do autor-narrador expressos pela abundância de adjetivos depreciativos $^{5}$ às práticas rituais de origem africana. O trecho termina por se configurar como uma peça genérica e abstrata com relação à ação da história que será narrada na sequência. Podemos usar os termos de Franco Moretti para dizer que mais do que a apresentação analítica da situação, a definição interna da cena, o que está em questão aqui é a avaliação ética e as reações de quem está de fora dela, no caso o narrador (MORETTI, 2009 , p. 850). Se considerarmos o que já foi dito sobre a caracterização do protagonista e mesmo sobre a novela de Macedo em termos geral, a sobredeterminação ética ou o ajuizamento do autor-narrador nessa passagem não

\footnotetext{
No trecho transcrito são 27 apenas o número de expressões adjetivadas (ou que funcionam com tal) que remetem negativamente a essas práticas.
} 
tem nada de estranho ou surpreendente. O objetivo, nesta altura, é chamar a atenção para a existência de graus e formas diferentes de ajuizamentos ao longo de todo o tecido narrativo. Talvez seja possível aventar a hipótese de que quanto mais distante do núcleo da ação narrativa mais forte e intensa é a presença dos juízos de valor do narrador, pois mais marcante é a presença da sua voz. Já quando a ação se instaura, ainda que essa seja sempre muito rarefeita e a própria voz do narrador nunca deixe de perder o controle sobre a matéria narrada, o percurso, as relações e as atitudes que os personagens estabelecem para si e entre si não deixam, ao menos em certa medida, de dividir com o narrador a perspectiva sobre os acontecimentos, dissolvendo parcialmente o mando desse.

Mas no caso do trecho acima transcrito se está no coração do ajuizamento do autor-narrador em que a avaliação ético-moral é tudo. O que se evidencia aqui, e a evidência salta aos olhos, é a rejeição acintosa e derrisória para o que pode ser entendido como a cultura do "outro". O caráter maligno, bárbaro, selvagem e grotesco com que é apresentado o que poderia ser chamado de manifestação de certa religiosidade popular é acachapante. Não se trata, bem entendido, de querer fazer com que Joaquim Manuel de Macedo pudesse se situar em outro campo de valores, em outro sistema ideológico ou em outra estrutura de sentimento que não aquele que seria possível para um letrado brasileiro e dos mais próximos e conformados ao establishment do segundo reinado brasileiro. Interessa-nos, na verdade, procurar explorar a particularidade brasileira do cruzamento e da imbricação de alta aspiração civilizatória e de progresso, do qual o gesto e a visão abolicionistas eram tidos como partícipes, com a mais brutal forma de subtração/nulidificação do outro e do seu sistema de valores cultural, aqui formulada no âmbito da ficção. Sob este aspecto, não parece soar estranho, paradoxal e, por que não dizer, abissal, que se misturem e se confundam num mesmo turbilhão ficcional espasmos emancipacionistas, elogio aos donos do arbítrio e do poder absoluto sobre o outro ${ }^{6}$ e repulsa e rejeição radical a quem se reconhece aparentemente com direito à liberdade, e não a ser mais que mera mercadoria.

Quando se disse, no começo deste artigo, que entre as duas opções que Macedo afirmara ter para contar os seus "quadros da escravidão" ele resolvera "optar" pela única que lhe seria possível, parece estar em questão não somente o fato de sua consciência de classe dominante pautar a compreensão do mundo, mas também de a figura do negro, e particularmente a do escravo negro,

\footnotetext{
6 Na novela "Simeão, crioulo", o narrador observa: "Nunca em parte alguma do mundo houve senhores mais humanos e complacentes do que no Brasil (...)" (MACEDO, 1991, p.62.).
}

estar como que, por assim dizer, interditada do ponto de vista social e simbólico - e, por consequência, literário. David Brookshaw, em seu estudo Raça e cor na literatura brasileira, observa que "não há evidências de que os escritores abolicionistas o considerassem [o negro] um ser humano com direito nato" (BROOKSHAW, 1983, p.41). Esta é uma formulação sobre qual se deve tirar todas os desdobramentos possíveis, pois ela pode estar no coração do que foi sugerido como a interdição da representação da figura do escravo negro na nossa ficção. Tudo indica que a visão que se tinha sobre o negro e sobre o escravo negro era a mesma entre abolicionistas e defensores da escravidão. Nesse ponto, vale destacar dois momentos da percepção sobre o estatuto do escravo negro no pensamento de homens que defendiam a instituição escravista no século XIX para se verificar como a ficção abolicionista de Macedo se põe em linha de continuidade com ambos, ao mesmo passo em que essas reflexões jogam luz ao estatuto ficcional dos personagens escravos do nosso autor.

O primeiro é de Carlos Augusto Taunay, tio do autor de Inocência, que, como proprietário de terras e produtor, produziu o Manual do agricultor brasileiro, escrito nos anos de 1820 mas publicado em 1839. O livro guarda um capítulo sobre como alocar da melhor maneira possível o trabalho escravo em todos os âmbitos da produção. Interessa-nos sublinhar a visão que o autor de origem francesa apresenta do escravo negro. Vejamos:

A inferioridade física e intelectual da raça negra, classificada por todos os fisiologistas como a última das raças humanas, a reduz naturalmente, uma vez que tenha contatos e relações com outras raças, e especialmente a branca, ao lugar ínfimo, e ofícios elementares da sociedade. Debalde procuram-se exemplos de negros cuja inteligência e produções admiram. O geral deles não nos parece suscetível senão do grau de desenvolvimento mental a que chegam os brancos na idade de quinze a dezesseis anos. A curiosidade, a imprevisão, as efervescências motivadas por paixões, a impaciência de todo o jugo e a inabilidade para se regrarem a si mesmo; a vaidade, o furor de se divertir, o ódio ao trabalho, que assinalam geralmente a adolescência dos europeus, marcam todos os períodos da vida dos pretos, que se pode chamar de homens-crianças e que carecem viver sob uma perpétua tutela: é pois indispensável conservá-lo, uma vez que o mal da sua introdução existe, em um estado de escravidão, ou próximo à escravidão; porém, esta funesta obrigação dá os seus péssimos frutos, e o primeiro golpe de vista nos costumes, moralidade e educação desengana o observador e o convence de que a escravidão não é um mal para eles, e sim para os senhores (TAUNAY, 2001, p. 53). 
Décadas depois, mais precisamente entre junho de 1867 e março de 1868, portanto muito próximo à publicação de Vítimas-algozes, José de Alencar lança a segunda série das Novas cartas políticas de Erasmo, dirigidas a D. Pedro II. Das sete cartas três delas defendem a instituição escravista, diante das pressões internas e externas que se armavam a favor da emancipação. Os argumentos de José de Alencar se dirigem a vários fatores para explicar e justificar a escravidão, e não deixando de compreender, num certo sentido, o quanto poderia ser positiva para a nação a contribuição africana para o caráter híbrido da cultura. Em que pese esse tipo de ponderação, o ponto de vista dominante de Alencar é o do rebaixamento do negro:

Não é menos injusta a outra imputação feita à humanidade de que o cativeiro não lima as raças bárbaras nem lhes infiltra raios de civilização.

Uma raça não se educa nem se instrui como um indivíduo.

(...)

Para educar uma raça são necessárias duas coisas: grande capacidade de vigor do povo culto para imergir a massa bruta e insinuar-se por todos os poros; longo tempo para que se efetue essa operação lenta e difícil. A raça africana tem apenas três séculos e meio de cativeiro. Qual foi a raça europeia que fez nesse prazo curto a sua educação?

(...)

Se algum dia, como é de esperar, a civilização se projetar pelo continente africano adentro, penetrando os povos da raça negra, a glória desse imenso acontecimento, amargue embora os filantropos, caberá exclusivamente à escravidão. Foi ela que preparou os precursores negros da liberdade africana. (ALENCAR, 2008, p. 92-94)

Os dois ensaios expressam a visão dominante sobre $o$ negro e sobre o escravo negro no Brasil ao longo de todo o século XIX por fração considerável da classe dominante, ainda que a origem histórica e social desse pensamento não tenha sido forjada por aqui ${ }^{7}$. Tanto Carlos A. Taunay quanto José de Alencar manifestam a posição corrente à época de que o negro é "raça inferior" ("a última das raças humanas"; "as raças bárbaras"). Para Taunay, os negros não somente tinham um desenvolvimento mental limitado ("os homens-crianças") como também demonstravam volubilidade e instabilidade emocional, dominados pela paixão que eram; além do que, mostravam-se incapazes de autocontrole pessoal e da disciplina exigida ao trabalho, a se considerar que a sua vinda da África tinha

\footnotetext{
Para uma exposição histórica ampla e detalhada da questão, ver $O$ problema da escravidão na cultura ocidental, de David Brion Davis (Rio de Janeiro, 2001).
}

como objetivo a exploração da sua força de trabalho. Interessante observar que os excessos figuram no âmbito das paixões, ou se quiser, dos instintos e das pulsões, o que é uma forma de supostamente compreender que o negro não tinha em qualquer esfera condições de exercer o domínio sobre a sua vida pessoal e coletiva. Sob este aspecto, a visão de Taunay do problema se formula por meio de um composto de déficits e de excessos: o primeiro ficando no âmbito físico-mental e o segundo no da estrutura dos sentimentos que formariam "a raça negra". Na resultante dos dois se justificaria o "estado da escravidão". Note-se que aqui a busca de legitimação do cativeiro é por assim dizer anterior à sua lógica social; não é intrínseca à dinâmica do próprio funcionamento social do escravismo, o que não deixa ser, sublinha-se, o nascedouro de muitas ideologias. De qualquer maneira, vale destacar esta particularidade da formulação de Taunay porque ela parece ressoar, como se verá, na ficção de Macedo. E também como nessa, o autor do Manual do agricultor brasileiro compreende que o mal maior da escravidão recai, não aos homens que se encontram sob o seu jugo, mas aos senhores na medida em que aquela atinge os costumes, a moralidade e a educação desses.

A posição de José de Alencar tem outro escopo argumentativo, conquanto a premissa básica para desenvolver o seu ponto de vista seja a mesma: a de que o negro faz parte das "raças bárbaras", primitivas. Enquanto para Taunay a escravidão seria uma necessidade intrínseca digamos à personalidade social do negro com o objetivo de extrair dele o sobretrabalho social necessário, já o autor de Senhora sustenta que a escravidão seria uma suposta etapa rumo a um patamar civilizatório mais avançado o qual os povos de origem africana ainda não teriam atingido. Todos os grupos sociais em algum momento teriam passado por esse processo ao longo da sua evolução histórica. O trabalho compulsório, pelo cativeiro, seria a principal forma de o "povo culto" imergir na "massa bruta" os seus valores culturais e morais supostamente superiores. Na busca de justificativa para a escravidão, José de Alencar cria um argumento que, ao contrário de Taunay, busca integrar o aspecto bárbaro e primitivo do negro como parte de um processo evolutivo da história da humanidade em geral. Assim, se o ponto de partida é a percepção da inferioridade da "raça negra", esta inferioridade não seria congenial do ponto de vista individual e coletivo, como a concebe Carlos A. Taunay, mas sobretudo histórico. Bem ao gosto do colonialismo ideológico de longa data, cabe às nações e aos grupos sociais "superiores" (leia-se: aos homens brancos pertencentes às classes dominantes do capitalismo central e periférico) a atribuição de integrar ao circuito civilizatório a horda de bárbaros que habitam 
a suas franjas, mesmo que ao preço da brutalidade intrínseca às relações escravista ${ }^{8}$.

Posto isso, voltemos à narrativa de Joaquim Manuel de Macedo para dizer que "Pai-Raiol, o feiticeiro", sugere trazer como determinação das suas linhas de força ficcionais as duas perspectivas expostas, que curiosamente se configuram numa tensão irresolvida. Para analisar a questão, retornemos, ainda mais especificamente, às citações referentes à figura do protagonista e à feitiçaria. Não parece haver dúvida que no caso da caracterização do Pai-Raiol se está no âmbito do que David Brookshaw, no seu estudo já referido, chamou da representação do escravo demônio, cujos traços são baseados em estereótipos facilmente reconhecidos pelos leitores (BROOKSHAW, 1983, p. 32). No entanto, a criação por meio do estereótipo ficcional do personagem não advém unicamente de um impulso particular do escritor ou de um tratamento específico relacionado somente ao discurso ficcional; ela sugere se estribar numa concepção social sobre o negro e o escravo negro orientada em afirmações sociais cujo vetor na parte e no todo é a negação do outro, o outro étnico e de classe, que aqui se confunde e se mistura. Assim, a caracterização do Pai-Raiol como ideação demoníaca, com a exacerbação de deformidades físicas que o definem e que se estendem e contaminam o seu campo moral (ele é traiçoeiro, ressentido, assassino etc.) parece ter linha de continuidade com as formulações de Carlos A. Taunay ao conceber o escravo negro como um feixe de déficits e de excessos físicos, mentais e emotivos, tudo no plano da sua mais absoluta negação. Por outro lado, vale destacar outra linha comum: refere-se ao tratamento que Macedo estabelece a seu personagem e ao seu mundo de valores em face da escravidão. Tanto a caracterização de Raiol quanto o olhar que o autornarrador lança para "feitiçaria" como constituinte do mundo dos negros não se sustentam como dimensões plenamente engendradas pela escravidão, ainda que no plano retórico o narrador force a conexão. Se Taunay descola as características da "raça negra" da dinâmica

\footnotetext{
8 No ensaio "Supressão e conservação do homem branco", o ensaísta alemão Robert Kurz faz ver que a noção do outro como "bárbaro" e "selvagem" não somente se estendeu para além do marco histórico do ressurgimento da escravidão no mundo moderno, como também constituiu a visão de mundo até mesmo de mentes e grupos sociais considerados avançados e progressistas à esquerda: "Mesmo Marx e Engels falavam sem qualquer embaraço em 'povos semicivilizados', ao passo que o emergente movimento operário socialdemocrata europeu não obteve qualquer consenso para condenação do colonialismo. Nos congressos socialistas internacionais, anteriores à Segunda Guerra Mundial, eram recebidas, sem qualquer estranheza, propostas como a formulada em 1907 pelo socialdemocrata alemão David, que via numa política colonial reformada e purificada um 'componente indispensável das aspirações culturais universais da socialdemocracia'. Por uma iniciativa da delegação britânica, uma resolução oficial de 1904 chegava ao ponto de reivindicar expressamente 'o direito dos habitantes de países civilizados a se estabelecerem em países cuja população se encontre em estágios menos avançados de desenvolvimento"'. (KURZ, 1997, p. 41-42)
}

interna à escravidão para até certo ponto legitimar e justificar essa, como se observou acima, o mesmo se pode dizer da representação que Macedo faz do escravo e do seu mundo (empírico e de valores). Os traços centrais de caracterização do personagem e de seu mundo parecem emanar da "natureza intrínseca" ao universo de origem afro-brasileira e do ajuizamento moral do narrador diante de ambos, e não dos mecanismos forjados "objetivamente" pela escravidão e figurados no plano formal e ficcional. Não se trata simplesmente do predomínio do preconceito étnico sobre o de classe, mas do apagamento geral da figura do outro, que faz com que uma perspectiva se sobreponha indiscriminadamente à outra, misturandoas e confundindo-as, como fundamento problemático da própria mimese. Daí o eixo representacional e explicativo do mundo ficcional oscilar entre as determinações raciais e/ou as de classe, via escravidão; entre, portanto, a visão "naturalizada" do negro e da escravidão de Taunay e a visão histórico-evolutiva de Alencar. Note-se que o aspecto geral da disformidade de Pai-Raiol e do grotesco da feitiçaria não se articula com as engrenagens sociais da escravidão ficcionalmente transfiguradas na esfera ficcional. Em que pese as marcas do cativeiro sirvam como elemento de definição do personagem, elas parecem mais imputadas à "natureza" do personagem do que à violência do sistema escravista; e o mesmo pode se dizer do ritual apresentado, no qual a alusão a sacerdotes africanos escravos e a alguns partícipes cativos do culto é o máximo de aproximação ao escravismo.

Para tentar articular com mais clareza e precisão de que modo a ficção conflui e reconfigura em si e para si certas visões correntes da época, talvez se possa dizer que a narrativa de "Pai-Raiol, o feiticeiro", acaba por se definir como uma espécie de estrutura dúplice e sobreposta, na qual, num primeiro momento, no âmbito da argumentação, descortina-se a instituição escravista como uma questão histórico-social, como relação - desigual - entre homens num dado lugar e num dado momento, aproximando-se aqui da perspectiva de Alencar diante o problema; num segundo, no plano da caracterização e, em parte, no das ações - esfera esta não estudada neste trabalho -, a apresentação se desenha mais em função da tipificação (negativa) do negro e do mundo em que se insere do que em função do argumento da narrativa centrado na lógica da escravidão - e, nesse ponto, a ficção de Macedo se conecta à visão de Taunay. Não se trata de imaginar que fosse possível a formalização estética do mundo escravista e do escravo negro, particularmente; ao contrário, o que se procurou demonstrar é justamente a impossibilidade de sua articulação no plano formal. A experiência social traumática da escravidão sugere interditar as formas de representação do outro, no caso, o escravo negro. Em razão dessa experiência social 
de base, o psicanalista Contardo Calligaris identifica o corpo do escravo como o "horizonte fantasmático universal das relações sociais" (CALLIGARIS, 1999, p. 30) na formação social brasileira, e, nesse sentido, "[o] escravo não é tanto um agente da enunciação, quanto o fantasma que parece sustentar o discurso de todos os agentes" (CALLIGARIS, 1999, p. 39) ${ }^{9}$. Por isso, muito provavelmente, a ficção abolicionista de Joaquim Manuel de Macedo estabeleça um duplo movimento, sem solução de continuidade formal, entre a percepção da escravidão como "evento histórico" e como "situação naturalizada", fazendo com que escravo e escravidão se tornem figuras fantasmáticas também na esfera ficcional.

\section{Referências}

ALENCAR, José de. Cartas a favor da escravidão. (Org. Tâmis Parron). São Paulo: Hedra, 2008.

BROOKSHAW, David. Raça e cor na literatura brasileira. Tradução de Marta Kirst. Porto Alegre: Mercado Aberto, 1983.

CALLIGARIS, Contardo. Hello Brasil!: notas de um psicanalista europeu viajando pelo Brasil. 5. ed. São Paulo: Escuta, 1996.
DAVIS, David Brion. O problema da escravidão na cultura brasileira. Tradução de Wanda Caldeira Brant. Rio de Janeiro: Civilização Brasileira, 2001.

KURZ, Robert. Supressão e conservação do homem branco. In Os últimos combates. 3. ed. Petrópolis: Vozes, 1997.

MACEDO, Joaquim Manuel. As vítimas-algozes. 3. ed. São Paulo: Scipione; Rio de Janeiro: Fundação Casa de Rui Barbosa, 1991.

MORETTI, Franco. O século sério. In: MORETTI, Franco (Org.). O romance: a cultura do romance. Tradução de Denise Bottmann. São Paulo: Cosac Naify, 2009.

SAYERS, Raimond S. O negro na literatura brasileira. Tradução de Antônio Houaiss. Rio de Janeiro: O Cruzeiro, 1958.

SUSSEKIND, Flora. As vítimas-algozes e o imaginário do medo. In: MACEDO, Joaquim Manuel. As vítimas-algozes. 3. ed. São Paulo: Scipione; Rio de Janeiro: Fundação Casa de Rui Barbosa, 1991.

TAUNAY, Carlos Augusto. Manual do agricultor brasileiro. (Org. Rafael de Bivar Marquese). São Paulo: Companhia das Letras, 2001.

Recebido: 14/11/16

Aprovado: 09/04/17

Contato: fcgil61@gmail.com

\footnotetext{
$\overline{9}$ Adapto a argumentação de Contardo Calligaris aos propósitos deste trabalho.
} 